\title{
TWENTY YEARS' EXPERIENCE WITH THE MEDTRONIC HALL VALVE
}

Eric G. Butchart, FESC, FRCS ${ }^{a}$

Hui-Hua Li, MD

Nicola Payne, BSc ${ }^{a}$

Keith Buchan, MD

Gary L. Grunkemeier, $\mathrm{PhD}^{\mathrm{b}}$
Objective: To assess the performance of the Medtronic Hall valve (Medtronic, Inc, Minneapolis, Minn) in one institution over a 20-year period.

Methods: Since 1979, Medtronic Hall valves have been used in 1766 procedures (736 aortic, 796 mitral, and 234 double). Patients were followed up prospectively at 6- to 12-month intervals for a total of 12,688 follow-up years. Anticoagulation data (international normalized ratio) were recorded for all patients (approximately 95,000 observations).

Results: Linearized rates of valve-related late death for aortic, mitral, and double valve replacement were $0.8 \% / \mathrm{y}, 0.9 \% / \mathrm{y}$, and $1.1 \% / \mathrm{y}$, respectively. Risk factors for late mortality were (relative risk) diabetes (1.9), decade of age (1.6), concomitant coronary artery bypass grafting (1.4), hypertension (1.3), non-sinus rhythm (1.3), large valve size (1.1), valve regurgitation (1.3), and male sex (1.2). For aortic, mitral, and double valve replacement, linearized rates (percent per year) of adverse events were valve thrombosis 0.04, 0.03, and 0.0; all thromboembolism 2.3, 4.0, and 3.4; stroke 0.6, 0.8, and 0.6; major hemorrhage 1.2, 1.4, and 1.6; and prosthetic endocarditis 0.4 , 0.4 , and 0.7. Risk factors for thromboembolism were (relative risk) mitral valve replacement (1.9), diabetes (1.8), hypertension (1.5), and history of embolism (1.4).

Conclusion: At 20 years the Medtronic Hall valve demonstrates excellent durability, good hemodynamic performance, and very low thrombogenicity, with a valve thrombosis rate lower than those reported for bileaflet designs. With this prosthesis, both survival and thromboembolic events are predominantly determined by patient risk factors. (J Thorac Cardiovasc Surg 2001;121:1090-100)
A the start of the new millennium, successful heart valve replacement has reached its fortieth anniversary. Despite 40 years of this type of surgery, many unanswered questions remain and the search continues for the "perfect" replacement device. Given that even native cardiac valves, although "perfect" in design, are imperfect in terms of resistance to disease processes and thrombus deposition, ${ }^{1}$ it is unlikely that a "perfect" valve will ever be produced. Nevertheless, it is now acknowledged that many of the "complications" tradi-

From the Department of Cardiothoracic Surgery, University Hospital of Wales, Cardiff, Wales, ${ }^{\mathrm{a}}$ and the Medical Data Research Centre, Providence Health System, Portland, Ore. ${ }^{\text {b }}$

Funding for this study was provided by Medtronic, Inc, Minneapolis, Minn.

Copyright () 2001 by The American Association for Thoracic Surgery

$0022-5223 / 2001 \$ 35.00+0 \quad \mathbf{1 2 / 1 / 1 1 3 7 5 4}$

doi: $10.1067 / \mathrm{mtc} .2001 .113754$ tionally attributed to prosthetic valves as "valve-related events" are, in fact, much more related to patient-related factors, surgical technique, and postoperative management. $^{2}$ Consequently, the results of valve replacement with the same device differ markedly between different population groups and especially between different age groups. ${ }^{3}$

Prosthetic valve assessment has been hindered by failure to take patient-related and management-related factors into account. In addition, cardiac surgeons' views have been colored by certain preconceptions about valve design that have been incorporated by valve manufacturers into their marketing strategy. There is a tendency to categorize all types of mechanical valves into 3 design categories (caged ball, tilting disc, and bileaflet) and to make all-embracing generalizations about the characteristics, sophistication, and modernity of each (ie, first generation, second generation). Worse still, and potentially more dangerous, recommendations on anticoagulation 
management are often based on broad design categories rather than individual prostheses. ${ }^{4,5}$

Because some of the early tilting disc valve designs were susceptible to valve thrombosis, many assume that this problem afflicts all tilting disc designs, whereas analysis of available data shows that this is clearly not the case. ${ }^{1}$ Similarly, bileaflet designs are perceived by many as more "modern," "third generation," and less susceptible to the problems of thrombosis and thromboembolism; however, some types of bileaflet valve have been shown to be more prone to valve thrombosis than tilting disc valves, especially in developing countries, ${ }^{6}$ and one recently introduced bileaflet valve had to be withdrawn from clinical use before trials were completed because of its high susceptibility to valve thrombosis. ${ }^{7}$

The Medtronic Hall tilting disc valve (Medtronic, Inc, Minneapolis, Minn) was introduced to clinical practice in 1977, the same year as the St Jude Medical bileaflet valve (St Jude Medical, Inc, St Paul, Minn). Although both are widely regarded as safe, reliable devices, it seems illogical that the latter is regarded by some as more "modern." A great deal of research and development went into the refinement of the tilting disc concept that eventually resulted in the production of the Medtronic Hall valve. ${ }^{8}$ Unique design features were incorporated to introduce very low susceptibility to thrombosis. In comparison with previous tilting disc designs, the relative size of the minor orifice was increased and the disc was made to lift out of the housing and rotate on opening, all features designed to improve washing of vulnerable points and eliminate areas of low velocity flow. In addition, housing cross members were placed in the center of blood flow and shaped to avoid causing flow disturbance.

Dissatisfaction with earlier tilting disc valve designs led to the introduction of the Medtronic Hall valve in Cardiff in 1979, and its use continues today.

\section{Methods}

Patient population. The patients were predominantly from South Wales, a region of the United Kingdom with much social deprivation and high unemployment that has a relatively high prevalence of both rheumatic and ischemic heart disease in relation to the rest of the United Kingdom and western Europe. Many of the Welsh patients, particularly the female patients, are of small stature, reflecting a relatively high requirement for small valve sizes. Use of the Medtronic Hall valve began in December 1979. From that date until July 1994, 1981 Medtronic Hall valves were implanted in 1720 patients in 1766 procedures. Of these procedures, $736(42 \%)$ were aortic valve replacements (AVRs), 796 (45\%) were mitral valve replacements (MVRs), and 234 (13\%) were double valve replacements (DVRs), including some sequential
DVRs. The very small number of tricuspid valve replacements $(n=12)$ and DVRs of mixed prosthesis type $(n=22)$ were excluded from the analysis. Patients were included whether the operation was performed on an elective or emergency basis. Clinical variables are summarized in Table I and operative data are shown in Table II.

Anticoagulation management. All patients received warfarin, starting on the first postoperative day. Patients unable to take oral warfarin at this time were given intravenous warfarin until they could take medication orally. Patients were given heparin only if their international normalized ratio (INR) was less than 2.0 on the fourth postoperative day. Individual INR measurements (approximately 95,000 observations) were recorded on all patients to carefully document their anticoagulation experience in relation to adverse events. The variation in INR values and the effect of an increase in anticoagulation intensity on event rates in this series have already been reported. ${ }^{9}{ }^{10}$ Since the analysis in 1991, the target INR has been 2.5 for AVR (3.0 if the patient is in atrial fibrillation or has poor left ventricular function) and 3.0 for MVR and DVR.

In addition to warfarin, some patients received dipyridamole at the discretion of their own physicians, but there was no prescribing consistency. Many patients discontinued the drug because of side effects and those who took it did so for only part of their follow-up. Overall, 13\% of AVR patients, $40 \%$ of MVR patients, and $32 \%$ of DVR patients took dipyridamole for part of their follow-up. The percentage of follow-up days taking dipyridamole was 7\% for AVR, $28 \%$ for MVR, and 23\% for DVR.

Follow-up. In 1979, the Medtronic Hall valve was still a relatively new prosthesis, and the first author (E.G.B.) implanted the first Medtronic Hall valve in the United Kingdom. This series was therefore planned as a prospective observational study from the outset with follow-up data recorded and entered into a computer at every outpatient visit for each patient. Most patients attended follow-up clinics at the University Hospital at intervals of 6 to 12 months. In the case of patients attending follow-up clinics at other hospitals, data were regularly retrieved from these sources also. At the time of this analysis, the small number of patients who had ceased to attend clinics regularly were contacted by telephone to update their follow-up.

Patients were also "flagged" in the National Health Service (NHS) Central Register, which maintains a death register for the United Kingdom. The NHS Register then notified the study investigators of all deaths of patients in the study and provided a copy of the death certificate. The hospital records of all patients who died in any hospital were scrutinized for further details. A detailed analysis of deaths earlier in this series has already been published, ${ }^{11,12}$ and the method of using NHS Register notification has previously been validated. ${ }^{13}$ Autopsies were performed in $48 \%$ of all deaths and $70 \%$ of sudden or unwitnessed deaths. ${ }^{11}$

Definitions and statistical analysis. For definitions of mortality and morbidity, standard guidelines were used. ${ }^{14}$ Early events refers to events within the first 30 postopera- 
Table I. Clinical variables

\begin{tabular}{|c|c|c|c|}
\hline & $A V R$ & $M V R$ & $D V R$ \\
\hline No. of replacements & 736 & 796 & 234 \\
\hline Male $(\%)$ & 69 & 27 & 43 \\
\hline \multicolumn{4}{|l|}{ Age $(y)$} \\
\hline Mean \pm SD & $60 \pm 11$ & $57 \pm 10$ & $59 \pm 9$ \\
\hline Range & $20-89$ & $13-79$ & $24-80$ \\
\hline \multicolumn{4}{|l|}{ NYHA (\%) } \\
\hline I-II & 60 & 41 & 32 \\
\hline III-IV & 40 & 59 & 68 \\
\hline \multicolumn{4}{|l|}{ Previous symptoms (\%) } \\
\hline Angina pectoris & 45 & 17 & 19 \\
\hline Orthopnea & 42 & 71 & 72 \\
\hline Myocardial infarction & 8 & 8 & 4 \\
\hline Heart failure & 34 & 56 & 67 \\
\hline Atrial fibrillation/flutter & 10 & 71 & 72 \\
\hline Thromboembolism & 6 & 16 & 13 \\
\hline \multicolumn{4}{|l|}{ Concomitant disease $(\%)$} \\
\hline Hypertension & 21 & 12 & 12 \\
\hline Diabetes mellitus & 5 & 7 & 6 \\
\hline Emergency operation (\%) & 10 & 7 & 6 \\
\hline \multicolumn{4}{|l|}{ Previous valve operation (\%) } \\
\hline Valve repair/valvotomy & 2 & 29 & 23 \\
\hline Valve replacement & 5 & 8 & 18 \\
\hline Valve disease $(\%)$ & & & $\mathrm{A} / \mathrm{M}$ \\
\hline Rheumatic & 9 & 74 & $81 / 84$ \\
\hline Endocarditis & 5 & 2 & $3 / 2$ \\
\hline Congenital & 51 & 1 & $3 / 0$ \\
\hline Ischemic & 0 & 4 & $0 / 0$ \\
\hline Degenerative & 30 & 7 & $0.4 / 3$ \\
\hline Valve calcification $(\%)$ & 86 & 49 & $65 / 56$ \\
\hline \multicolumn{4}{|l|}{ Operative diagnosis $(\%)$} \\
\hline Stenosis & 59 & 53 & $30 / 46$ \\
\hline Regurgitation & 21 & 26 & $42 / 26$ \\
\hline Mixed lesion & 20 & 21 & $28 / 28$ \\
\hline
\end{tabular}

$A / M$, Aortic position/mitral position

tive days. Late events refers to occurrences at all subsequent times.

Early events ( $<30$ days) were expressed as percentages and late events ( $>30$ days) were expressed as percent per year. All events, including those in the first 30 days, were included in the event-free curves for mortality and morbidity. Right censored data, including patient survival, valve-related reoperation, obstructive valve thrombosis, prosthetic endocarditis leading to reoperation or death, and paravalvular leak were constructed by means of the actuarial method of Kaplan and Meier. ${ }^{15}$ Interval-censored data such as thromboembolism and bleeding complications that were known to have occurred during a particular interval of follow-up were assessed by means of the Turnbull generalization of the Kaplan-Meier method and by the conventional Kaplan-Meier method taking the midpoint of follow-up intervals as the time of failure. Because the 2 methods yielded very similar results, probably because most intervals are small, ${ }^{16}$ we used the latter method. The significance of differences between groups was tested by means of the log-rank method. The Weibull distribution model showed good agreement with the Kaplan-
Table II. Operative data

\begin{tabular}{cccc}
\hline & $A V R$ & $M V R$ & $D V R(A / M)$ \\
\hline Prosthesis size (mm) (\%) & & & \\
20 & 13 & 0 & $23 / 0$ \\
21 & 23 & 0 & $33 / 0$ \\
22 & 3 & 0 & $1 / 0$ \\
23 & 31 & 4 & $26 / 3$ \\
25 & 21 & 23 & $12 / 20$ \\
27 & 8 & 32 & $4 / 41$ \\
29 & 2 & 31 & $1 / 28$ \\
31 & 0 & 8 & $0 / 7$ \\
33 & 0 & 2 & $0 / 1$ \\
Concomitant CABG (\%) & 21 & 14 & 14
\end{tabular}

$A / M$, Aortic position/mitral position.

Meier method to estimate the freedom from thromboembolism. Instantaneous hazard functions of thromboembolism were derived from the Weibull fits by taking the derivative of the cumulative hazard function. The Cox proportional hazard model was used to assess the relationship between various risk factors and patient survival. ${ }^{17}$ All analyses were performed using the SPLUS software package, version 2000 (MathSoft, Inc, Seattle, Wash).

\section{Results}

Early mortality. The operative mortality was $4.2 \%$ for AVR, $7.7 \%$ for MVR, and $12 \%$ for DVR. There were 2 early valve-related deaths $(0.3 \%)$ in AVR patients, $5(0.6 \%)$ in MVR, and $1(0.4 \%)$ in DVR (Table III). Risk factors for early mortality were diabetes, previous valvotomy, concomitant coronary artery bypass grafting, preoperative regurgitation, preoperative New York Heart Association (NYHA) class, and decade of age (Table IV).

Follow-up. Follow-up information is summarized in Table V. The total cumulative follow-up was 12,679 patient-years; 5120 patient-years for AVR (mean 7.0 years), 6053 patient-years for MVR (mean 7.6 years), and 1506 patient-years for DVR (mean 6.6 years). With follow-up to 1998, 64 patients were lost, for $96 \%$ completeness. The distribution of NYHA class preoperatively and at $5(\mathrm{n}=979)$ and $10(\mathrm{n}=419)$ years postoperatively is shown in Fig 1. Analysis of functional status changes showed an improvement in $69 \%$ of AVR patients, $73 \%$ of MVR patients, and $74 \%$ of DVR patients at 5 years. Improvement was sustained at 10 years in $66 \%, 64 \%$, and $73 \%$, respectively.

Survival. A total of 631 patients (211 AVR, 325 MVR, 95 DVR) died in the late postoperative period. The late mortality expressed as linearized rate was 4.1\%/y for AVR, 5.4\%/y for MVR, and 6.3\%/y for DVR. Valve-related late death occurred in $40(0.8 \% / y)$ 
Table III. Valve-related deaths

\begin{tabular}{|c|c|c|c|c|c|c|}
\hline & \multicolumn{2}{|c|}{$A V R$} & \multicolumn{2}{|c|}{$M V R$} & \multicolumn{2}{|c|}{$D V R$} \\
\hline & $\operatorname{Early}(n)$ & Late $(n)$ & $\operatorname{Early}(n)$ & Late (n) & $\operatorname{Early}(n)$ & Late $(n)$ \\
\hline Stroke & 0 & 15 & 2 & 17 & 0 & 2 \\
\hline Thrombosis & 0 & 1 & 0 & 0 & 0 & 0 \\
\hline Major bleeding & 1 & 18 & 0 & 22 & 0 & 8 \\
\hline PVE & 1 & 6 & 3 & 14 & 1 & 7 \\
\hline Total & $2(0.3 \%)$ & $40(0.8 \% / y)$ & $5(0.6 \%)$ & $53(0.9 \% / y)$ & $1(0.4 \%)$ & $17(1.1 \% / y)$ \\
\hline
\end{tabular}

Table IV. Logistic regression risk factors for early deaths

\begin{tabular}{lcccc}
\hline & Coefficient & $S E$ & P value & $R R$ \\
\hline Preoperative NYHA class & 0.442 & 0.186 & .017 & .045 \\
Diabetes & 0.790 & 0.393 & .040 & 2.203 \\
Concomitant CABG & 0.606 & 0.294 & .004 & 1.833 \\
Previous valvotomy & 0.714 & 0.248 & .043 & 2.042 \\
Valve regurgitation & 0.618 & 0.306 & .018 & 1.855 \\
Decade of age & 0.343 & 0.145 & 1.410
\end{tabular}

$S E$, Standard error; $R R$, relative risk; $N Y H A$, New York Heart Association; $C A B G$, coronary artery bypass grafting.

AVR patients, $53(0.9 \% / y)$ MVR patients, and 17 (1.1\%/y) DVR patients (Table III). Overall patient survivals, including early and late deaths, at 10 and 15 years were $64 \%$ and $45 \%$ for AVR, $58 \%$ and $36 \%$ for MVR, and $47 \%$ and $30 \%$ for DVR (Fig 2). However, survival was heavily influenced by the need for concomitant coronary surgery (Figs 3 and 4) and by valve lesion (Figs 5 and 6). Survival after AVR for aortic stenosis without coronary disease (Fig 5) was almost identical to that for the age- and sex-matched general population for the first $7 \frac{1}{2}$ years (data from English Life Tables, published by the United Kingdom Office for National Statistics).

Risk factors for late mortality were diabetes, decade of age, concomitant coronary artery bypass grafting, hypertension, valve regurgitation, large valve size, nonsinus rhythm, and male sex (Table VI).

Complications. There were no mechanical failures and no cases of suture entrapment.

Thrombosis. Four patients had obstructive valve thrombosis, 2 with AVR and 2 with MVR. Presentation was insidious over several weeks in each case. Two patients (1 AVR, 1 MVR) were treated by thrombectomy and 2 by re-replacement with another Medtronic Hall valve. All 4 were postmenopausal women in their 70s. Three patients survived reoperation. The patient who died had severely impaired left ventricular function caused by coronary disease and subendocardial fibrosis. Valve thrombosis may have been a terminal
Table V. Follow-up and death

\begin{tabular}{lccc}
\hline & $A V R$ & $M V R$ & $D V R(A / M)$ \\
\hline No. of valves & 736 & 796 & $224 / 225$ \\
No. of valve replacements & 736 & 796 & 234 \\
No. of patients & 726 & 779 & $226^{*}$ \\
Operative mortality (\%) & 4.2 & 7.7 & 12 \\
Lost patients & 25 & 29 & 10 \\
Follow-up & & & \\
$\quad$ Maximum (y) & 18 & 18 & 18 \\
$\quad$ Mean \pm SD (y) & $7.0 \pm 4$ & $7.6 \pm 5$ & $6.5 \pm 5$ \\
$\quad$ Total (pt-y) & 5120 & 6053 & 1506 \\
$\quad$ Completeness (\%) & 96.6 & 96.4 & 95.7 \\
Late death & & & \\
$\quad$ Total & 211 & 325 & 95 \\
$\quad$ Rate (\%/y) & 4.1 & 5.4 & 6.3 \\
\hline
\end{tabular}

$A / M$, Aortic position/mitral position.

*Eleven sequential DVR patients also appear as previous AVR or DVR.

event associated with low cardiac output in this case. The 3 remaining patients had all had anticoagulation interruption: One diabetic patient had not received anticoagulants for 4 months after an intracerebral hemorrhage; one grossly obese patient with hypercholesterolemia had her warfarin stopped 3 times in the course of a month in preparation for a minor orthopedic operation that was canceled twice; and an asthmatic smoker receiving steroids had been given vitamin $\mathrm{K}$ in addition to having the anticoagulation regimen interrupted. All these patients also had pulmonary infec- 


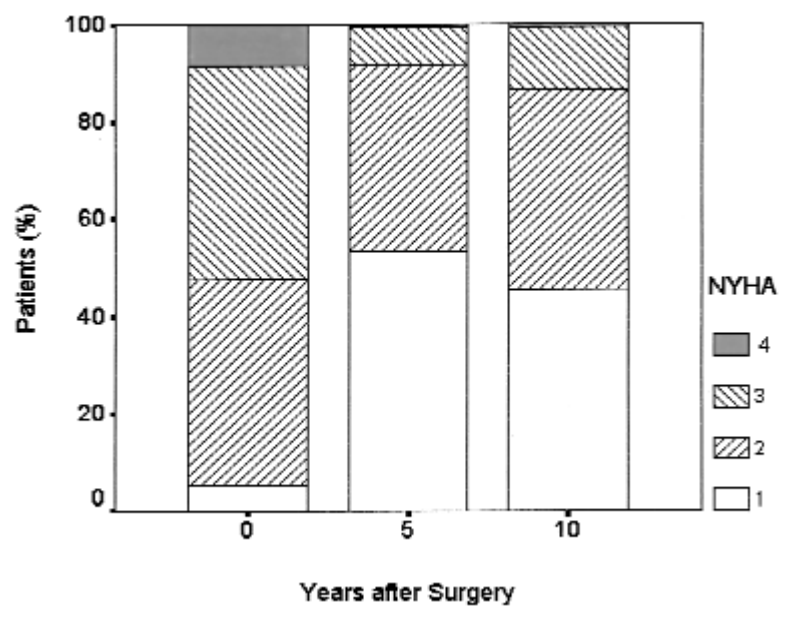

Fig 1. NYHA classification change at 5 and 10 postoperative years.

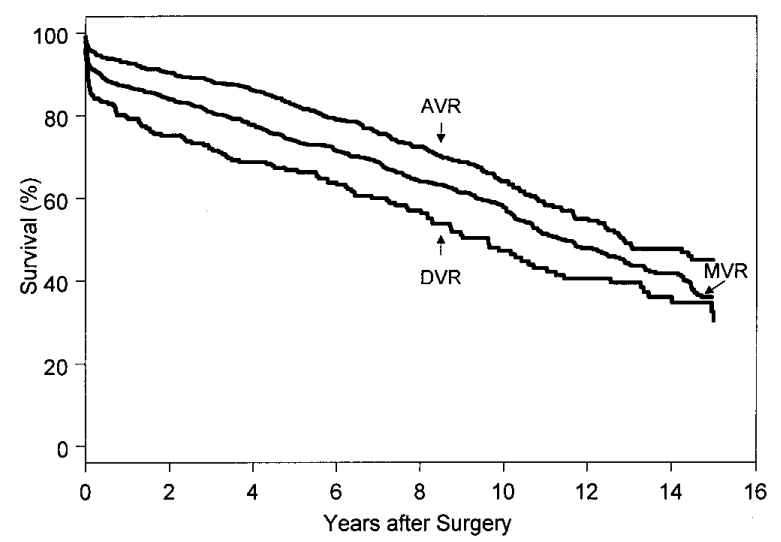

Fig 2. Survival of patients by valve position.

tions in the period preceding the onset of valve thrombosis, raising the possibility that valve thrombosis was due to a combination of a pre-existing prothrombotic state, the prothrombotic effects of pulmonary infection, and anticoagulation interruption. The detailed case histories of all 4 patients and their risk factors for valve thrombosis have already been described. ${ }^{18}$ No valve thromboses occurred among the DVR patients. Among the $70 \%$ of patients with sudden, rapidly progressing, or unwitnessed death submitted to autopsy, there were no cases of valve thrombosis. ${ }^{11}$ The linearized rates of valve thrombosis were $0.04 \% / y$ for AVR and $0.03 \% / y$ for MVR.

Thromboembolism. A total of 443 thromboembolic events occurred in this series, 340 of which were minor, almost all transient or reversible ischemic attacks (transient ischemic attacks or reversible ischemic neurologic

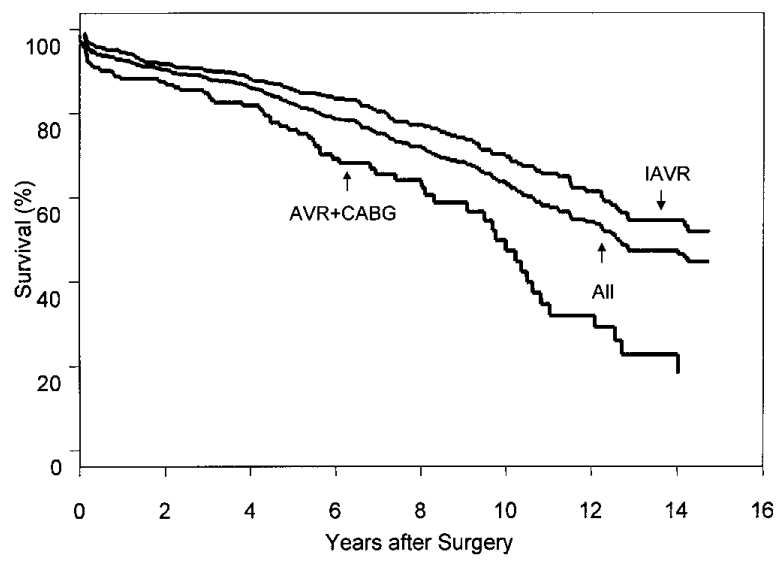

Fig 3. Survival after AVR with and without coronary artery bypass grafting. IAVR, First-time isolated AVR $(\mathrm{n}=507)$; All, all AVR ( $\mathrm{n}=735) ; A V R+C A B G$, First-time AVR with coronary artery bypass grafting $(\mathrm{n}=148)$.

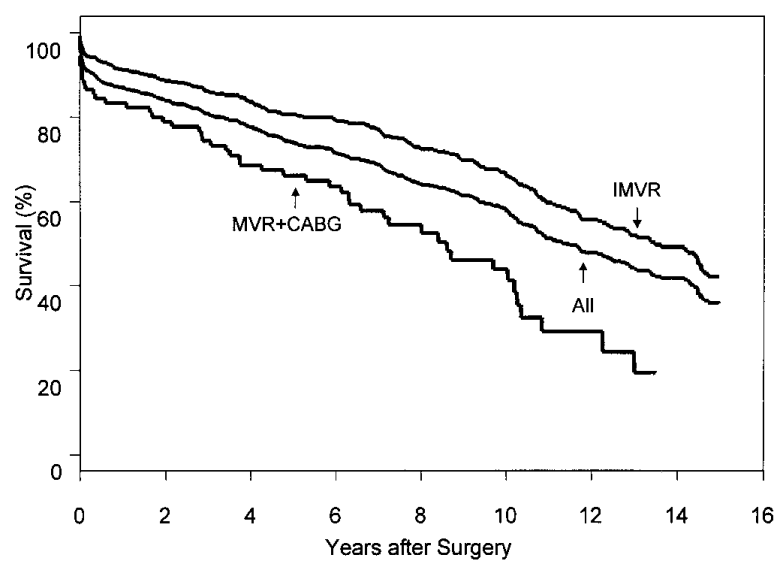

Fig 4. Survival after MVR with and without coronary artery bypass grafting. IMVR, First-time isolated MVR ( $=471)$; $A l l$, all MVR $(\mathrm{n}=796) ; M V R+C A B G$, first-time MVR with coronary artery bypass grafting $(\mathrm{n}=90)$.

deficits); 103 were major (almost all strokes) that led to permanent damage or death. The linearized rates of minor events were $1.7 \% / y$ for AVR, $3.2 \% / y$ for MVR, and $2.8 \% / y$ for DVR. The linearized rates of stroke were $0.6 \% / y$ for AVR, $0.8 \% / y$ for MVR, and $0.6 \% / y$ for DVR. The linearized rates of overall thromboembolism were 2.3\%/y for AVR, 4.0\%/y for MVR, and 3.4\%/y for DVR (Table VII). Overall, $10 \%$ of patients had 1 thromboembolic event and 6\% had more than 1 event. Only $4 \%$ of AVR patients and $5 \%$ of MVR patients had a stroke at any time. In patients who had multiple events at 1 fol- 


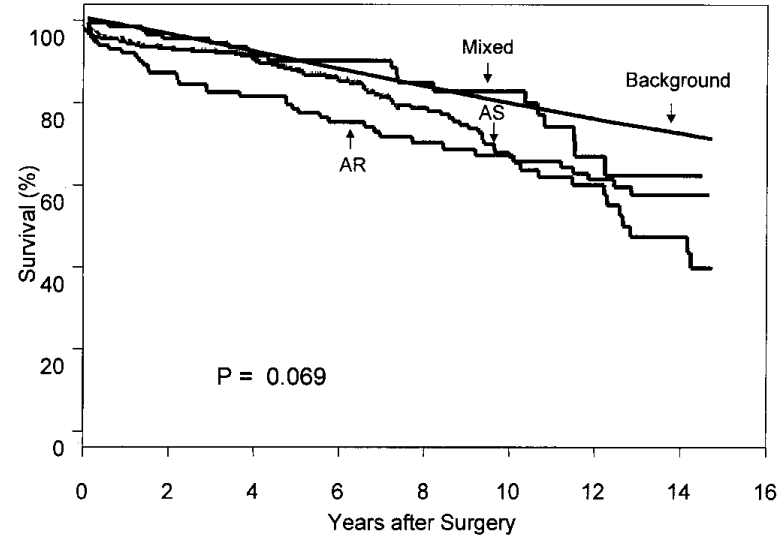

Fig 5. Survival after AVR only, by valve lesion. Mixed, Mixed lesions $(\mathrm{n}=102) ; A S$, aortic stenosis $(\mathrm{n}=298) ; A R$, aortic regurgitation $(\mathrm{n}=106)$.

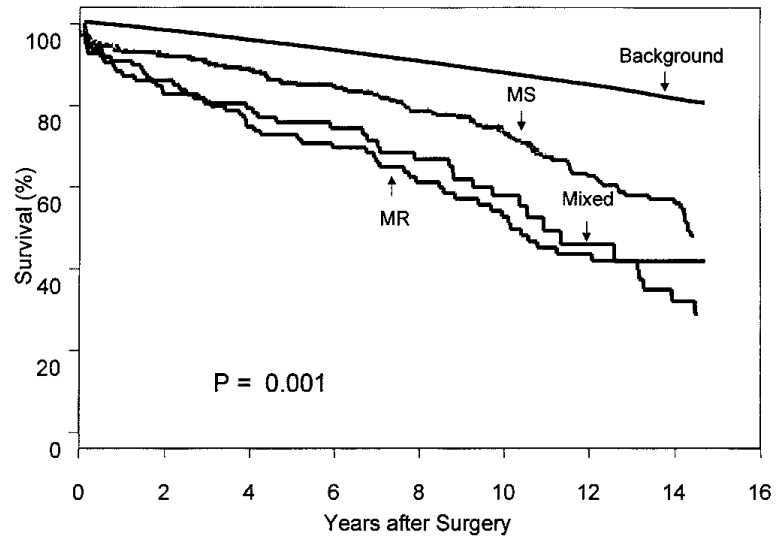

Fig 6. Survival after MVR only by valve lesion. Mixed, Mixed lesions ( $\mathrm{n}=91) ; M S$, mitral stenosis $(\mathrm{n}=273) ; M R$, mitral regurgitation $(\mathrm{n}=106)$.

Table VI. Cox regression risk factors for late deaths

\begin{tabular}{lcccc}
\hline & Coefficient & SE & P value & $R R$ \\
\hline Hypertension & 0.276 & 0.118 & .019 & .000 \\
Diabetes & 0.618 & 0.149 & .006 & 1.318 \\
Concomitant CABG & 0.306 & 0.111 & .000 & 1.354 \\
Valve size & 0.065 & 0.017 & .007 & 1.068 \\
Valve regurgitation & 0.239 & 0.089 & .000 & 1.269 \\
Decade of age & 0.476 & 0.048 & .021 & 1.610 \\
Male sex & 0.215 & 0.093 & .019 & 1.240 \\
Non-sinus rhythm & 0.250 & 0.106 & 1.284
\end{tabular}

$S E$, Standard error; $R R$, relative risk; $C A B G$, coronary artery bypass grafting.

low-up interval, the linearized rate was computed in such a way that applied the worst severity of the event to all events. The overall actuarial estimates of freedom from thromboembolism at 10 and 15 years were $84 \%$ and $79 \%$ for AVR, $77 \%$ and $65 \%$ for MVR, and $76 \%$ and $72 \%$ for DVR (Fig 7). Thromboembolism risk was highest during the first 30 days: computed as a "1-month" linearized rate, it was $8 \% / y$ and $33 \% / y$ for AVR and MVR, respectively. In contrast, the linearized rate for all thromboembolism was $2 \% / \mathrm{y}$ for AVR and $4 \% / \mathrm{y}$ for MVR after the first month, declining further during longterm follow-up (Fig 8). Significant risk factors for thromboembolism were MVR, diabetes, hypertension, and a history of previous embolism (Table VIII).

Major hemorrhage. A total of 193 (69 AVR, 94 MVR, 24 DVR) major bleeding events met the definition of the guidelines. ${ }^{14}$ The linearized rates of major hemorrhage were $1.2 \% / y$ for AVR, $1.4 \% / y$ for MVR, and $1.6 \% / y$ for DVR. The actuarial estimates of freedom from major hemorrhage at 10 and 15 years were
$87 \%$ and $83 \%$ for AVR, $87 \%$ and $81 \%$ for MVR, and $87 \%$ and $84 \%$ for DVR. The rate of major hemorrhage also was highest in the early postoperative period, in keeping with the known effect of anticoagulation in unmasking occult disease. ${ }^{19,20}$

Prosthetic valve endocarditis. Prosthetic valve endocarditis developed in 59 patients, 33 of whom died ( 1 at reoperation). The remainder had successful reoperations. The linearized rates of endocarditis were $0.4 \% / y$ for AVR, $0.4 \% / y$ for MVR, and $0.7 \% / y$ for DVR. The actuarial estimates of freedom from endocarditis at 10 and 15 years were $96 \%$ and $95 \%$ for AVR, $95 \%$ and 94\% for MVR, and $94 \%$ and $94 \%$ for DVR.

Paravalvular leaks. Paravalvular leak in the absence of endocarditis occurred in 13 patients: 2 AVR, 9 MVR, and $3 \mathrm{DVR}$, the latter all in the mitral position. The linearized rates for AVR, MVR, and DVR were $0.04 \% / y$, $0.1 \% / y$, and $0.2 \% / y$, respectively. The thin sewing ring of the size 20 and 22 aortic prostheses was not associated with any paravalvular leaks. The actuarial freedom 


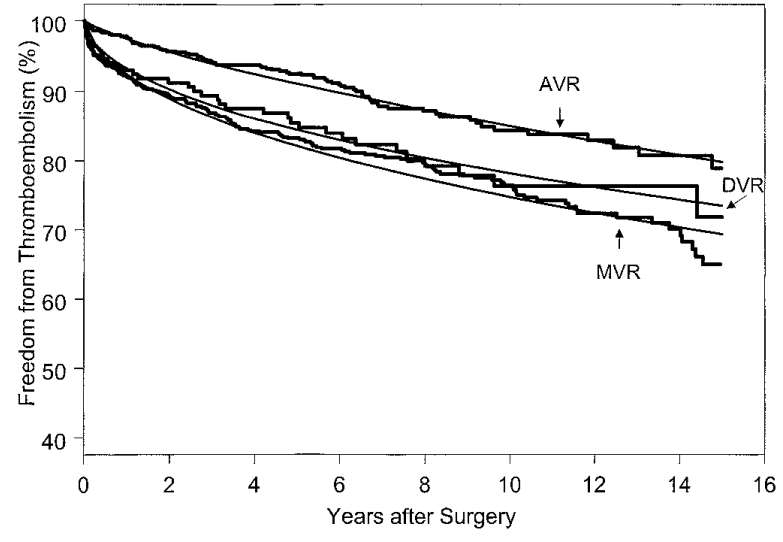

Fig 7. Thrombobembolism by valve position for AVR, MVR, and DVR. The stepped curves are the Kaplan-Meier estimates and the smooth curves are fitted from the parametric Weibull distribution.

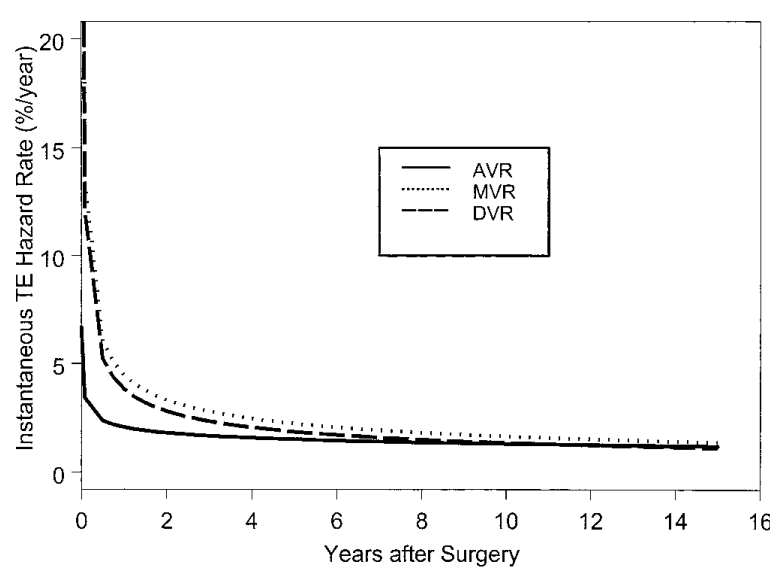

Fig 8. Instantaneous hazard function curves for thromboembolism by valve position. The hazard functions are derived from the Weibull fits (Fig 7) by taking the derivative of the cumulative hazard function.

Table VII. Postoperative valve-related complications

\begin{tabular}{|c|c|c|c|c|c|c|}
\hline & \multicolumn{2}{|c|}{$A V R$} & \multicolumn{2}{|c|}{$M V R$} & \multicolumn{2}{|c|}{$D V R$} \\
\hline & Early (\%) & Late (\%/y) & Early $(\%)$ & Late (\%/y) & Early (\%) & Late $(\% / y)$ \\
\hline Thromboembolism & 0.7 & 2.3 & 2.7 & 4.0 & 1.6 & 3.4 \\
\hline Minor & 0.4 & 1.7 & 1.4 & 3.2 & 1.6 & 2.8 \\
\hline Major & 0.3 & 0.6 & 1.3 & 0.8 & 0.0 & 0.6 \\
\hline Thrombosis & 0.0 & 0.04 & 0.0 & 0.03 & 0.0 & 0.0 \\
\hline Major bleeding & 0.8 & 1.2 & 1.1 & 1.4 & 0.0 & 1.6 \\
\hline PVE & 0.1 & 0.4 & 0.4 & 0.4 & 0.4 & 0.7 \\
\hline Repair & 0.0 & 0.04 & 0.0 & 0.1 & 0.4 & 0.2 \\
\hline Explant & 0.1 & 0.4 & 0.0 & 0.3 & 0.0 & 0.5 \\
\hline Reoperation & 0.1 & 0.4 & 0.0 & 0.4 & 0.4 & 0.7 \\
\hline
\end{tabular}

$P V E$, Prosthetic valve endocarditis.

Table VIII. Cox regression risk factors for postoperative thromboembolism

\begin{tabular}{lcccc}
\hline & Coefficient & SE & P value & $R R$ \\
\hline MVR & 0.635 & 0.156 & .000 & 1.886 \\
Diabetes & 0.578 & 0.274 & .035 & 1.783 \\
Hypertension & 0.397 & 0.193 & .040 & 1.487 \\
Previous embolism & 0.324 & 0.087 & .000 & 1.383 \\
\hline
\end{tabular}

$S E$, Standard error; $R R$, relative risk.

from reoperation for paravalvular leak at 15 years was 99.7\% for AVR, 99\% for MVR, and 98\% for DVR.

Reoperation and explantation. Any operation that repaired, altered, or replaced a previously inserted valve was called a reoperation. There were 58 reoperations ( 22 AVR, 25 MVR, 11 DVR), 48 of which (19 AVR, 21 MVR, 8 DVR) resulted in explantation. The linearized rates of reoperation were $0.4 \% / y$ for AVR, $0.5 \% / y$ for
MVR, and $0.7 \% / y$ for DVR. The linearized rates of explantation were $0.4 \% / y$ for AVR, $0.4 \% / y$ for MVR, and $0.5 \% / y$ for DVR. The actuarial estimates of freedom from reoperation at 15 years were $96 \%$ for AVR, 95\% for MVR, and 93\% for DVR. The actuarial estimates of freedom from explantation at 15 years were $96 \%$ for AVR, 96.5\% for MVR, and 94\% for DVR. The reasons for reoperation are listed in Table IX. 
All valve-related complications. The linearized rates of all valve-related complications were $4.3 \% / y$ for AVR, $6.2 \% / y$ for MVR, and 6.4\%/y for DVR. The actuarial estimates of freedom from all valve-related complications at 10 and 15 years were $72 \%$ and $60 \%$ for AVR, $61 \%$ and $50 \%$ for MVR, and $61 \%$ and $52 \%$ for DVR.

\section{Discussion}

The most important variables that measure prosthetic valve performance and permit meaningful comparison between prostheses are mechanical integrity, hemodynamic characteristics, and thrombogenicity, inasmuch as these are truly prosthesis-related factors, specific to the type of prosthesis, which influence survival and quality of life. Other adverse events that occur after valve replacement and that are classified by the reporting guidelines ${ }^{14}$ as "prosthesis related," for example, endocarditis and major hemorrhage, are events that occur in all large prosthetic valve series but are not "caused" by the specific type of prosthesis; rather, they are prosthesis associated but much more related to patient factors and aspects of postoperative management, particularly in the case of hemorrhage, the quality of anticoagulation control, and the target INR range. Durability and hemodynamic performance can be measured according to rigid objective criteria, but thrombogenicity is difficult to measure. It has been shown that thromboembolic rates vary considerably among different series of the same prosthesis, ${ }^{3}$ probably because of differences in patient population (age, ethnicity, geography, and concomitant disease), antithrombotic management, and methods of data collection. ${ }^{21}$ Thromboembolic rates after valve replacement have also been shown to be heavily influenced by known stroke risk factors. ${ }^{22}$ Hence, thromboembolic rates provide a poor measure of thrombogenicity unless allowances can be made for all other influences in the analysis. We have used this approach in earlier analyses (vide infra). Although also to some extent dependent on patient factors and anticoagulation management, valve thrombosis rates give a much better indication of prosthesis thrombogenicity. ${ }^{21}$

The goal of the Medtronic Hall design was to improve on previous tilting disc designs with the aim of improving durability and hemodynamic performance and reducing thrombogenicity. The results of this 20-year experience show that these aims have been achieved. There were no mechanical failures. Hemodynamic measurements were not performed on all patients, but echocardiographic assessment of mitral prostheses was carried out early in the study,
Table IX. Reasons for reoperation

\begin{tabular}{lrrr}
\hline & $A V R$ & $M V R$ & $D V R$ \\
\hline Endocarditis & 17 & 13 & 7 \\
Paravalvular leak & 2 & 9 & 3 \\
Thrombosis & 2 & 2 & 0 \\
Tissue ingrowth & 0 & 1 & 1 \\
Recurrent embolism & 1 & 0 & 0 \\
Total & 22 & 25 & 11 \\
\hline
\end{tabular}

with peak rate of increase of left ventricular dimension during diastole being used for the assessment. These evaluations showed that the hemodynamic performance of the Medtronic Hall valve was significantly better than that of Björk-Shiley (Shiley, Inc, Irvine, Calif) and Starr-Edwards prostheses (Baxter Healthcare Corp, Edwards Division, Santa Ana, Calif) of the same size, and left ventricular filling in 29- or 31-mm prostheses was not significantly different from that of subjects with normal mitral valves. In patients with 27-mm and 29- to 31-mm prostheses, $91 \%$ and $89 \%$, respectively, improved by one class or more. ${ }^{23}$ In the current analysis, the NYHA performance status of most patients improved by at least one class, an improvement that was maintained at 10 years. In patients whose dominant lesion was aortic stenosis and who did not have coronary disease, arguably the "purest" test of prosthesis performance, survival was almost identical to that of the age- and sex-matched general population for the first $7 \frac{1}{2}$ years and not significantly different from the general population out to 10 years (Fig 5). This provides a combined indirect assessment of hemodynamic effectiveness and freedom from any excess of life-threatening events in comparison with the general population. Both characteristics of valve performance are probably attributable to optimum blood flow through the prosthesis.

Optimum flow characteristics not only provide the best relief of transvalvular gradients, allowing left ventricular mass regression after AVR, for example, but also, by providing good "washing" of all components and minimizing flow disturbance, reduce the risk of thrombus deposition and platelet activation. ${ }^{21}$ The Medtronic Hall valve has been shown to have an equivalent hemodynamic performance to the St Jude Medical valve in the larger sizes and to have superior hemodynamic performance to it in the smaller aortic sizes, ${ }^{24}$ particularly with increasing cardiac output. ${ }^{25} \mathrm{It}$ is also possible to orientate the Medtronic Hall aortic prosthesis so that the larger orifice faces the greater 
curvature of the ascending aorta, thereby creating nearphysiologic flow. ${ }^{26,27}$ The same can never be achieved with a bileaflet valve, because it has 3 orifices ${ }^{26}$; consequently, valve gradients across the Medtronic Hall valve in its optimum orientation are lower than can be achieved with the St Jude Medical valve in any orientation. ${ }^{28}$ This improved and less turbulent flow in comparison with the bileaflet design may contribute to the trend toward greater left ventricular mass regression that has been reported with the Medtronic Hall valve in comparison with the St Jude Medical valve. ${ }^{29}$ It may also partly explain the finding of less hemolysis with the Medtronic Hall valve when normally functioning Medtronic Hall and St Jude Medical valves are compared. ${ }^{30}$ Anderson and associates ${ }^{31}$ have shown normalization of left ventricular mass index after AVR with the Medtronic Hall valve, using ultrafast computed tomographic scan, even in the smallest sizes 20 and 21. Furthermore, a recent study has shown more rapid left ventricular mass regression with the Medtronic Hall valve in comparison with the St Jude Medical valve after AVR. ${ }^{32}$

In the series reported here, the aortic valve was implanted preferentially with the larger orifice toward the greater curvature of the aorta, rotating the valve only if this position caused the downward deflection of the disc to impinge on the septum. The majority of aortic prostheses $(89.1 \%)$ were thus in the optimum orientation. The good long-term survival after AVR in comparison with the general population in this series may relate to the very low turbulence and low gradients produced by the prosthesis in this orientation. In an earlier analysis, we have shown that the gradually increasing incidence of stroke with advancing age in this series did not differ significantly from the age-related background incidence of stroke in the general population. ${ }^{33}$ This finding may also reflect the beneficial effect of optimum flow in combination with low thrombogenicity. Transcranial Doppler detection of high-intensity transient signals has recently shown significantly fewer high-intensity transient signals with the Medtronic Hall valve in its optimum orientation both in comparison with its worst orientation and in comparison with the St Jude Medical valve in any orientation, in keeping with this hypothesis. ${ }^{34}$ Using data from earlier analysis of this series, we have shown that cerebrovascular events after AVR were closely related to well known stroke risk factors, that is, hypertension, cigarette smoking, diabetes, and arterial disease. Patients who were in sinus rhythm, normotensive, nonsmokers, not diabetic, and who had no coronary artery disease had no cerebrovascular events during a 13 -year follow-up period. ${ }^{22}$

The mitral prosthesis in this series was implanted with the larger orifice posteriorly in almost all patients. This orientation has been shown to permit flow patterns within the left ventricle similar to those seen physiologically ${ }^{35}$ and probably contributed to the almost normal rate of ventricular filling seen with the larger sized mitral prostheses referred to above. ${ }^{23}$

Thromboembolic events after mitral valve replacement are determined largely by conditions that promote relative stagnation in the left atrium (atrial fibrillation, increased left atrial size, residual mitral gradient, and impaired left ventricular function) and the extent to which these adverse conditions are controlled by effective anticoagulation. ${ }^{21}$ In earlier analyses, we have shown that the optimum INR of 3.0 prevents most serious thromboembolic events in patients with the Medtronic Hall valve in the mitral position ${ }^{10}$ and that the incidence of events has an association with known stroke risk factors and a seasonal fluctuation with winter predominance, in keeping with pulmonary infection as a trigger factor. ${ }^{36}$

Much earlier in this series, we reported a zero rate of valve thrombosis with the Medtronic Hall valve. At that stage, in 1988, in just over 1000 patients, there had been no cases of valve thrombosis. ${ }^{37}$ Since then 4 patients have had obstructive valve thrombosis, but the overall incidence remains extremely low $(0.04 \% / y)$. A previously published analysis of these patients identified the combination of the prothrombotic effects of pulmonary infection and anticoagulation interruption as the probable interaction that triggered thrombus deposition on the prosthesis in 3 of 4 patients. ${ }^{18}$

The valve thrombosis rate reported here is lower than that reported for other large series of mechanical valves and some series of bioprostheses with comparable lengths of follow-up. ${ }^{3}$ Eleven of 12 St Jude Medical mitral valve series with more than 300 valve-years reported since 1989 had higher thrombosis rates. For these 11 series with a total of 28,000 years, the mean thrombosis rate was $0.13 \% / y$ (range $0.07 \% / y$ $0.45 \% / y){ }^{3}$

The very good thromboembolic performance of the Medtronic Hall valve in this series has been achieved with low-intensity anticoagulation, giving the additional benefit of a low incidence of serious bleeding events. To place it in context, this needs to be compared with the background incidence of major hemorrhage in the general population. Data from the placebo arms of several anticoagulation trials show that major hemorrhage occurs at a linearized rate between $0.7 \% / \mathrm{y}$ and $1.6 \% / \mathrm{y}$ 
(mean $1.2 \% / y$ ) in a population of approximately the same age group as this valve series. ${ }^{38-40}$ The linearized rates for AVR, MVR, and DVR (1.2\%/y, 1.4\%/y, and $1.6 \% / y$, respectively) fall within the range in the general population, indicating that the patients in this series were not exposed to an excess risk as the result of their anticoagulation management.

Overall, our results at 20 years demonstrate that the Medtronic Hall valve has excellent durability, very good hemodynamic performance, and exceptionally low thrombogenicity, leading to good long-term survival with low complication rates and a very low requirement for reoperation. Contrary to the perceptions of many surgeons about the supposed design advantages of bileaflet valves, our long-term results support the large number of recent reports showing that more physiologic flow conditions can be created by the Medtronic Hall valve. In our view this prosthesis offers superior hemodynamic performance and lower thrombogenicity than currently available bileaflet designs and should now be considered the gold standard against which other prostheses should be judged.

Received for publication Sept 5, 2000; revisions requested Oct 24, 2000; revisions received Dec 18, 2000; accepted for publication Dec 20, 2000.

Address for reprints: Eric G. Butchart, FESC, FRCS, Department of Cardiothoracic Surgery, University Hospital of Wales, Heath Park, Cardiff CF14 4XN, United Kingdom.

\section{REFERENCES}

1. Butchart EG. Thrombogenicity, thrombosis and embolism. In: Butchart EG, Bodnar E, editors. Current issues in heart valve disease: thrombosis, embolism and bleeding. London: ICR Publishers; 1992. p. 172-205.

2. Butchart EG. Prosthetic heart valves. In: Verstraete M, Fuster V, Topol EJ, editors. Cardiovascular thrombosis. Philadelphia: Lippincott-Raven; 1998. p. 395-414.

3. Grunkemeier GL, Li H-H, Naftel DC, Starr A, Rahimtoola SH. Long-term performance of heart valve prostheses. Curr Probl Cardiol 2000;25:73-156.

4. Stein PD, Alpert JS, Dalen JE, Horstkotte D, Turpie AGG. Antithrombotic therapy in patients with mechanical and biological prosthetic heart valves. Chest 1998;114(Suppl):602S-10S.

5. Verstraete M, Prentice CRM, Samama M, Verhaeghe R. A European view on the North American Fifth Consensus on Antithrombotic Therapy. Chest 2000;117:1755-70.

6. Kinsley RH, Colsen PR, Antunes MJ. Medtronic Hall valve replacement in a third world population group. Thorac Cardiovasc Surgeon 1983;31(Suppl II):69-72.

7. Bodnar E. The Medtronic Parallel valve and the lessons learned. J Heart Valve Dis 1996;5:572-3.

8. Hall KV, Kaster RL, Woien A. An improved pivotal disc-type prosthetic heart valve. J Oslo City Hosp 1979;29:3-21.

9. Butchart EG, Lewis PA, Kulatilake ENP, Breckenridge IM. Anticoagulation variability between centres: implications for comparative prosthetic valve assessment. Eur J Cardiothorac Surg 1988;2:72-81.

10. Butchart EG, Lewis PA, Bethel JA, Breckenridge IM. Adjusting anticoagulation to prosthesis thrombogenicity and patient risk factors: recommendations for the Medtronic Hall valve. Circulation 1991:84(Suppl):III-61-9.

11. Rooney SJ, Moreno de la Santa P, Lewis PA, Butchart EG. Sudden death in a large prosthetic valve series based on a single prosthesis: experience with the Medtronic Hall valve. J Heart Valve Dis 1994;3:5-9.

12. Butchart EG. The significance of sudden and unwitnessed death after heart valve replacement. J Heart Valve Dis 1994;3:1-4.

13. Lewis PA, Wilson RJ. The use of the NHS Central Register when estimating patient survival. J Heart Valve Dis 1995;4(Suppl I):S13-6.

14. Edmunds LH Jr, Clark RE, Cohn LH, Grunkemeier GL, Miller DC, Weisel RD. Guidelines for reporting morbidity and mortality after cardiac valvular operations. J Thorac Cardiovasc Surg 1996;112:708-11.

15. Kaplan EL, Meier P. Nonparametric estimation from incomplete observations. J Am Stat Assoc 1958;53:457-81.

16. Law CG, Brookmeyer R. Effects of mid-point imputation on the analysis of doubly censored data. Stat Med 1992;11:1569-78.

17. Cox DR Regression methods and life tables. J R Stat Soc 1972;34:187-220.

18. Butchart EG. Fibrinogen and leukocyte activation-The keys to understanding prosthetic valve thrombosis? J Heart Valve Dis 1997;6:9-16.

19. Landefelt CS, Rosenblatt MW, Goldman L. Bleeding in outpatients treated with warfarin: relation to the prothrombin time and important remediable lesions. Am J Med 1989;87:153-9.

20. Landefeld CS, Beyth RJ. Anticoagulant-related bleeding: clinical epidemiology prediction and prevention. Am J Med 1993;95: 315-28.

21. Butchart EG. Thrombogenesis and its management. In: Acar J, Bodnar E, editors. Textbook of acquired heart valve disease. London: ICR Publishers; 1995. p. 1048-120.

22. Butchart EG, Moreno de la Santa P, Rooney SJ, Lewis PA. Arterial risk factors and cerebrovascular events following aortic valve replacement. J Heart Valve Dis 1995;4:1-8.

23. Butchart EG, Griffiths BE, Breckenridge IM. Clinical and echocardiographic assessment of the Medtronic Hall valve: experience with 370 implanted valves. Thorac Cardiovasc Surg 1983;31(Suppl II):81-4.

24. Aris A, Ramirez I, Camara L, Carreras F, Borras X, Pons-Llado G. The $20 \mathrm{~mm}$ Medtronic Hall prosthesis in the small aortic root. J Heart Valve Dis 1996;5:459-62.

25. Marcus RH, Heinrich RS, Bednarz J, Lupovitch S, Abruzzo J, Borok R, et al. Assessment of small-diameter aortic mechanical prostheses: physiological relevance of the Doppler gradient, utility of flow augmentation, and limitations of orifice area estimation. Circulation 1998;98:866-72.

26. Kleine P, Perthel M, Nygaard H, Hansen SB, Paulsen PK, Riis C, et al. Medtronic Hall versus St. Jude Medical mechanical aortic valve: downstream turbulences with respect to rotation in pigs. J Heart Valve Dis 1998;7:548-55.

27. Laas J, Kleine P, Hasenkam MJ, Nygaard H. Orientation of tilting disc and bileaflet aortic valve substitutes for optimal hemodynamics. Ann Thorac Surg 1999;68:1096-9.

28. Travis BR, Heinrich RS, Ensley AE, Gibson DE, Hashim S, 
Yoganathan AP. The hemodynamic effects of mechanical prosthetic valve type and orientation on fluid mechanical energy loss and pressure drop in in vitro models of ventricular hypertrophy. $\mathbf{J}$ Heart Valve Dis 1998;7:345-54.

29. Dolan MS, Castello R, St. Vrain JA, Puri S, Dressler FA, Fiore A, et al. Relationship of left ventricular hypertrophy regression and outflow turbulence following aortic valve replacement. Circulation 1996;94(Suppl I):721.

30. Skoularigis J, Essop MR, Skudicky D, Middlemost SJ, Sareli P. Frequency and severity of intravascular hemolysis after left-sided cardiac valve replacement with Medtronic Hall and St. Jude Medical prostheses, and influence of prosthetic type, position, size and number. Am J Cardiol 1993;74:587-91.

31. Anderson WA, Ilkowski DA, Eldredge J, Cha R, Chen C, Waters $D$, et al. The small aortic root and the Medtronic Hall valve: ultrafast computed tomography assessment of left ventricular mass following aortic valve replacement. J Heart Valve Dis 1996;5(Suppl III):S329-35.

32. Kleine P, Hasenkam MJ, Nygaard H, Perthel M, Wesemeyer D, Laas J. Tilting disc versus bileaflet aortic valve substitutes: intraoperative and postoperative hemodynamic performance in humans. J Heart Valve Dis 2000;9:308-12.

33. Butchart EG, Grunkemeier GL, Li HH, Buchan K. Evaluation of results after aortic valve replacement: comparison to general population data facilitates standardization. Cardiovasc Eng 2000; 5:113.
34. Kleine P, Perthel M, Hasenkam JM, Nygaard H, Hansen SB, Laas J. Downstream turbulence and high intensity transient signals (HITS) following aortic valve replacement with Medtronic Hall or St. Jude Medical valve substitutes. Eur J Cardiothorac Surg 2000;17:20-4

35. Jones M, Eidbo EE. Doppler color flow evaluation of prosthetic mitral valves: experimental epicardial studies. J Am Coll Cardiol 1989;13:234-40.

36. Butchart EG, Moreno de la Santa P, Rooney SJ, Lewis PA. The role of risk factors and trigger factors in cerebrovascular events after mitral valve replacement: implications for antithrombotic management. J Card Surg 1994:9(Suppl):228-36.

37. Butchart EG, Lewis PA, Grunkemeier GL, Kulatilake N, Breckenridge IM. Low risk of thrombosis and serious embolic events despite low-intensity anticoagulation: experience with 1,004 Medtronic Hall valves. Circulation 1988;78(Suppl):I-6677.

38. Stroke Prevention in Atrial Fibrillation Study Group Investigators. Preliminary report of the Stroke Prevention in Atrial Fibrillation Study. N Engl J Med 1990;322:863-8.

39. Sixty Plus Reinfarction Study Research Group. Risk of long-term oral anticoagulant therapy in elderly patients after myocardial infarction. Lancet 1982;1:64-8.

40. European Atrial Fibrillation Trial Study Group. Secondary prevention in non-rheumatic atrial fibrillation after transient ischaemic attack or minor stroke. Lancet 1993;342:1255-62.

\section{Availability of Journal back issues}

As a service to our subscribers, copies of back issues of The Journal of Thoracic and Cardiovascular Surgery for the preceding 5 years are maintained and are available for purchase from Mosby until inventory is depleted. The following quantity discounts are available: $25 \%$ off on quantities of 12 to 23, and one third off on quantities of 24 or more. Please write to Mosby, Subscription Customer Service, 6277 Sea Harbor Dr, Orlando, FL 32877, or call 800-654-2452 or 407-345-4000 for information on availability of particular issues and prices. If unavailable from the publisher, photocopies of complete issues may be purchased from Bell \& Howell Information and Learning, 300 N Zeeb Rd, Ann Arbor, MI 48106-1346; 734-761-4700 or 800-521-0600. 